\title{
Commitment to diversity in Ethiopian public universities: Perception of veteran instructors
}

\author{
Authors: Gara Latchanna ${ }^{1}$; Tariku Sime Gutu ${ }^{2}$ \\ Affiliation: Professor of Education, Andhra University, India ${ }^{1}$; \\ Department of Teacher Education and Curriculum Studies, Jimma University, Ethiopia ${ }^{2}$ \\ E-mail: garalatchanna@gmail.com ${ }^{1}$; senagutu@gmail.com ${ }^{2}$
}

DOI: 10.26821/IJSRC.6.4.2018.6405

\begin{abstract}
Human diversity has existed from time immemorial. But it has got momentous concern as interaction among people increases and the landscape changes primarily because of demographic, socio-economic, cultural and political changes driven by science and technology. Currently, diversity and diversity management are no longer mere topical issues for debate in educational institutions in general and higher learning institutions in particular, but are facts to be confronted. This study intended to examine the institutional commitment of Ethiopian public universities to diversity. Mixed research approach with Complementary design using parallel phase was employed to secure authentic information from 180 seasoned instructors across six universities. The finding revealed that diversity oriented strategic policies and programs are peripheries though attempts are made especially to control potential flashpoints. Institution based recommendations tailored to the needs of the campus community are made.
\end{abstract}

Keywords: Diversity, Institutional commitment, diversity management

\section{INTRODUCTION}

\subsection{Background of the study}

It is apparent and axiom of our time that we are living in an era of great change. The ancient Greek philosopher Heraclitus said, "You cannot step into the same river twice." If we were to rephrase his quote using contemporary terminology, we might simply say that "change is constant and inevitable". Indeed, the current movement going on within and across nations testifies this notion. There is a tremendous change, predominantly, because of demographic, socio-economic, cultural, and political interactions between and among various institutions, regions and countries of the world than ever before. On the other hand, driven by science and technology in the $21 \mathrm{st}$ century, economic forces are shrinking space, time, the series of life styles, and cultural differences mainly into a working interdependent global society [1]. The interdependence makes us all aware of how closely we are in touch with the actions of people who are far distant from us. Other global practices such as human migration, social media, and economic liberalization concurrently reshape local environments continously, bringing the seemingly 'distant' into close proximity. This is resulted in ubiquitous term called diversity; human diversity in this study. It is conceptualized differently among scholars. In this study, however, refers to the differences in major diversity dimensions namely ethnic background, religion, language and gender $[2,3]$.

Currently, diversity and diversity management are not only an element of academic issues for debate in educational institutions in general and higher learning institutions in particular, but also a fact to be dealt with. What particularly ignites argument on issues related to diversity and diversity management practices in higher education institutions is the urgency to create safe, welcoming, inclusive and conflict free learning environments composed of people of diverse backgrounds [4].As an institution established for academic purpose, higher education institutions are places where myriad issues of diversity are recognized and promoted to succeed in teaching, research and community service; tripartite missions of higher education institutions. This makes higher education institutions (HEIs) a right place to enhance every individuals' personal and social developments especially through creating welcoming campus climate 
Volume 6 Issue 4 April 2018

for all $[5,6]$.Research findings associated with diversity and diversity management in higher education reveal the educational outcomes of diverse institutional environment. These are summarized in to three interdependent benefits: Individual, Institutional and Societal.

Individual benefits refer to the ways in which the educational experiences and outcomes of individual students are enhanced by the existence of diversity on campus. Research evidence regarding the individual benefits of diversity suggests that diversity improves student growth and development in the cognitive, affective, and interpersonal domains [7].Particularly, researches from the social sciences have identified a number of specific ways in which students who attend universities with a diverse student population benefit in comparison to students with homogeneous student bodies [7,8]. Arguments in favor of learning in diversified environment, suggests that the benefits of a diverse student body are realized not by only disadvantaged groups, but also by privileged students. In short, it serves all students despite their differences in their identity and background.

Empirical evidences also show that diversity benefits institutions constituted with diversified population. It refers to the ways in which diversity enhances the effectiveness of an academic organizations or institutions in line with their major purposes: teaching, research and community services. Celebrated research works show that diverse working groups are more productive, creative and innovative than homogenous groups and suggest developing the composition of diversified groups $[9,10]$.It is an instrument to produce citizens who can understand the world beyond the horizon and fit to the globalized world. In due course the process uplifts the status of the institution and facilitates the move towards its vision and mission.

Societal benefits deals with the ways in which diversity in higher education institutions impacts quality of life issues in the larger society. Perhaps of most prominence here are the ways in which a diverse workforce and diverse student enrollments contribute to the achievement of democratic ideals of equity and access, the development of an educated and involved citizenry, and the provision of services to groups in the society who are badly underserved [7].

In order to secure, promote and maximize the aforementioned benefits, the commitment of higher education institutions is imperative. Institutional commitment to diversity, or lack thereof, is presumably determines the nature of the learning environment. The commitment can be articulated in an institutional mission, policies programs and practices $[11,12]$.

\subsection{Problem Statement}

Many prominent figures in the field of diversity and diversity management attest to the importance of the role and benefits of addressing diversity in higher education [13, 14]. Ethiopia, the general context of this study, is one of the highly diverse Sub-Saharan African countries where ethnic, religious, gender and other diversity dimensions have been the historic and common questions of its society. Its modern history is also characterized by; inter alia, ethnic tension, gender imbalances and religious conflicts [15]. Since the beginning of modern education, a number of legal and policy documents were produced. Most of them were partial in addressing major diversity dimensions of the country such as ethnicity, religion and language $[16,17]$. As compared to previous trends, the current government fundamentally established on the essence of diversity through its legal and policy documents. Although diversity issues are enshrined in legal documents and framed in policies and programs, different scholarships and researches have been revealing the glaring state of challenges associated with addressing diversity and its management in higher education institutions $[18,19,20]$. The assessment of the research trends show that the role of institutional commitment in creating welcoming environment is not addressed very well. This can be argued from three perspectives. Primarily most of them were limited to few universities and difficult to draw nationwide implication. Second, the focus areas were on ethnic interrelation status than institutional commitment role. Finally, most of them were used qualitative research where other aspects of quantitative views might be forgotten. It is important, therefore, to investigate the nature of institutional commitment for diversity in public universities across the country.

\subsection{Objectives}

Since objectives describe the expected eventual achievements, the study was intended to realize the following objectives related with institutional commitment to diversity in Ethiopian public universities

1. Examine the intuitional commitment of public universities

2. Figure out the employed diversity management strategies 
Volume 6 Issue 4 April 2018

3. Identify the hindering factors for creating diverse learning environment

4. Investigate the response differences based on diversity dimensions

Based on the objectives, the research questions framed for the study were:

$>$ To what extent universities are committed to diversity

$>$ How do universities manage diversity?

$>$ What are the challenges of managing diversity on campus?

$>$ Is there a significant difference between and within different groups of the respondents based on dimensions of diversity?

\section{Theoretical Framework}

All organizations in general and educational institutions in particular are influenced by external and internal forces. The focus of this study is related with internal issues associated with commitment to diversity to create welcoming campus climate. In line with this concept, Hurtado and her associates [4] developed multicontextual and complex diverse learning framework. They proposed different campus level dimensions. Structural dimension is the central concern in this research. In the dimension, institutional commitment is manifested through three interrelated policies and practices: broader context for institutional policies and practices, specific policies or practices that form and reform the environment, and processes to improve the climate for diversity on an organizational level [4].Broader institutional policies and practices are intentional and unintentional changes associated with diversity and diversity management that emanate from the socio-historical, political, and local community contexts [4] to reshape organizational behavior in addressing diversity. Regarding specific commitments to diversity issues are components related with such as curriculum, teaching methods and assessment strategies. Fostering inclusive campus climate is another aspect of institutional commitment through having a clear definition of diversity that influences practice, working with multiple elements of organizational culture, creating shared responsibility for assessing, planning, and improving the climate and having comprehensive evaluation and assessment system.

\section{Methodology}

Taking in to account the nature of the research problem, mixed research approach was employed. From the various research designs that fit within the general framework of mixed approach, the Complementary design using parallel phase (embedded designs) was selected for the essential features of the study go in line with the characteristics of this method. Its prime purpose was to gain authentic data not secured through primary approach (Quantitative) by substantiating through qualitative data. The rationale is that a single data set is not sufficient to answer different research questions. This design is, therefore, a means through which one data set provides a supportive, secondary role in a study based primarily on the other data type [21].

Six universities were involved in the study selected randomly from different generation universities. Generation here refers to the time of establishment of the universities which has human and material resource implication to implement institutional programs. One hundred eighty (180) instructors participated in the study selected through multilevel sampling technique. Questionnaire and interview were used as data collection instruments to obtain authentic information. Besides the vision, mission and value statements of the universities were scrutinized in line with diversity. Quantitative data were analyzed using descriptive statistical techniques. Qualitative data, on the other hand, were analyzed based on the theme framed integrated with quantitative data. The instruments' validity and reliability were confirmed scientifically based on the contemporary theoretical and empirical procedures.

\section{Findings and Discussion}

Instructors' responses are presented at two levels. The first describes the mean score of each item meant to indicate the institutional commitment and the specific items with highest and lowest mean scores. The second presents the interview results in line with the theme created based on areas of institutional commitment to diversity.

Table 1 portrays the hierarchical order of the measures institutions take to address diversity in their institutions. Accordingly, the first item which says "the university clearly states diversity issues in its vision and missions" has got the highest mean score (3.97).The fundamental aspect that helps to know the overarching purpose behind the establishment of a given institution is its vision, mission, goals and core values. The result unarguably indicates the institutions commitment at strategic place. The other extreme point with lowest mean result (2.35) refers to the item "University rewards academic and administrative staff for their participation in diversity efforts". This shows in many institutions there is no trend where staff 
Volume 6 Issue 4 April 2018

members are encouraged for taking part in diversity related activities. Between the two end point results, the mean score distribution ranges from 2.69 to 3.56.Next to institutional commitment through its vision, mission, goals and values, most of the respondents voiced the effort of the university to create a diverse and inclusive community in different formal and informal programs. The instructors were also asked whether the university promotes the appreciation of cultural differences in various institutional programs or not and their reply shows mean score of 2.97. This is an important area of institutional commitment to address diversity for all programs and policies are meant to serve the campus community as its best level.
Another specific question raised to examine the university commitment was "The university creates an equal opportunity for university community to succeed regardless of differences in gender, religion, ethnicity and language" The mean result (2.87) confirms the better agreement of the respondents. The status of communicating diversity issues in various publications through its outlets bore 2.73 mean score. Providing an environment for free and open expression of ideas, opinions, and beliefs labeled the second lowest result (2.69) from the bottom.

Table1. Instructors' response about institutional commitment to diversity

\begin{tabular}{|c|c|c|c|c|}
\hline Item & $\mathrm{N}$ & Sum & Mean & Std. Deviation \\
\hline Clearly states diversity issues in its vision and missions & 180 & 715 & 3.97 & 1.126 \\
\hline strives in creating a diverse and inclusive community & 180 & 640 & 3.56 & 1.338 \\
\hline $\begin{array}{l}\text { Has clear disciplinary procedures to address issues of harassment or } \\
\text { discrimination }\end{array}$ & 180 & 588 & 3.27 & 1.482 \\
\hline $\begin{array}{l}\text { Promotes the appreciation of cultural differences in various institutional } \\
\text { programs }\end{array}$ & 180 & 534 & 2.97 & 1.509 \\
\hline $\begin{array}{l}\text { Creates an equal opportunity for university community to succeed } \\
\text { regardless of differences in gender, religion, ethnicity and language. }\end{array}$ & 180 & 517 & 2.87 & 1.465 \\
\hline $\begin{array}{l}\text { Accurately reflects the diversity of the campus community in } \\
\text { publications (e.g. brochures, website) }\end{array}$ & 180 & 491 & 2.73 & 1.421 \\
\hline $\begin{array}{l}\text { Provides an environment for free and open expression of ideas, opinions, } \\
\text { and beliefs }\end{array}$ & 180 & 485 & 2.69 & 1.450 \\
\hline $\begin{array}{l}\text { rewards academic and administrative staff for their participation in } \\
\text { diversity efforts }\end{array}$ & 180 & 423 & 2.35 & 1.380 \\
\hline Valid N (listwise) & 180 & & & \\
\hline
\end{tabular}

In order to examine the specific frequencies and percentages of each item, the two extremes (highest and lowest) are taken as a sample and portrayed in the charts. As indicated in the table, the highest mean is for the item "Clearly states diversity issues in its vision and missions" and the lowest is for "rewarding academic and administrative staff for their participation in diversity efforts". The response across the scale for both items is represented in the following pie charts. Chart 1 portrays the frequencies and percentages of the respondents on the item "Clearly states diversity issues in its vision and missions". Chart 2 on the other hand illustrates frequencies and percentages of the respondents of the item "rewards academic and administrative staff for their participation in diversity efforts" 
Volume 6 Issue 4 April 2018

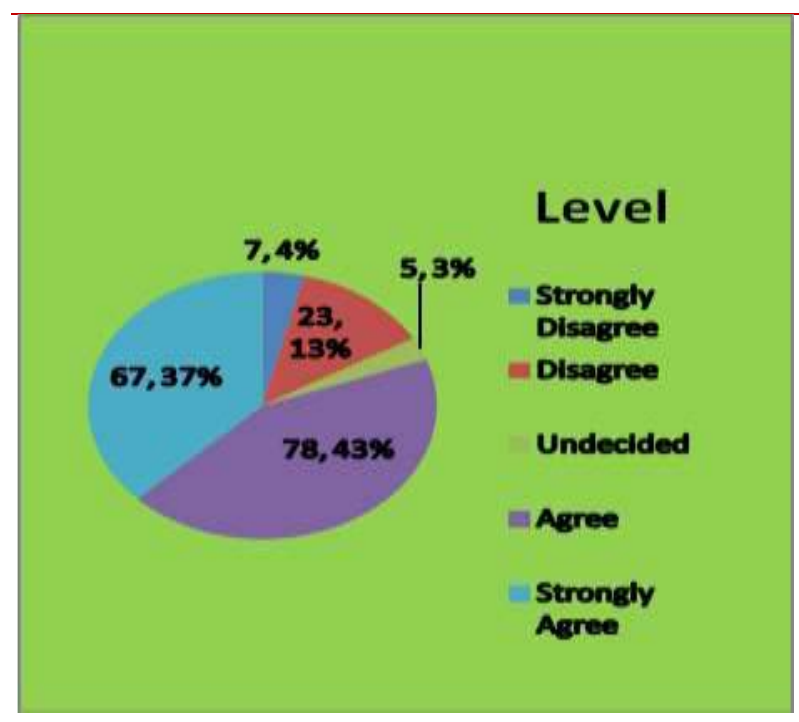

Chart.1.Item with highest mean score

Concerning their perception about the place of diversity in institutional vision and mission statements, $78(43 \%)$ of the respondents agreed with the statement. The next highest frequency and percentage is also taken by more than one-third of the respondents (37\%) who put their preference under 'Strongly Agree'. The combined result shows that $145(80 \%)$ of the respondents felt diversity issues are inculcated in the institutions' vision and mission statements. Regarding rewarding academic and administrative staff for their contribution in creating welcoming campus climate as indicated in chart two ,63(35\%) of the respondents strongly disagreed with the statement. The next highest frequency and percentage also strengthens the aforementioned response for 58(32\%) of them disagreed with the statement. If the frequency and percentage add up, it makes $121(67 \%)$ respondents who gravitate towards the umbrella term of 'Disagreement' albeit differences in degree. Only 26\% of the participants go for agreement category.

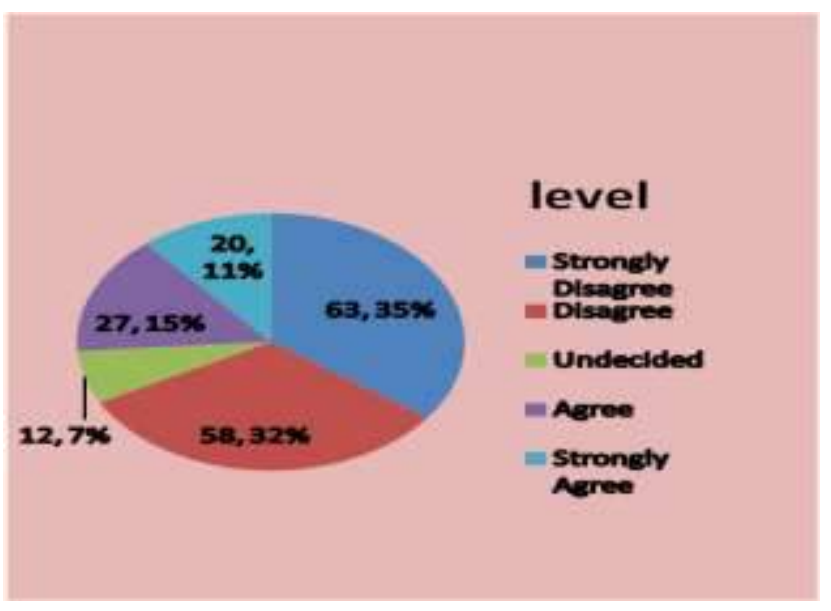

Chart 2. Item with lowest mean score
In order to examine the instructors' response difference in terms of different groups such as gender, experience, academic status and generation of the universities were made. First, an independent-samples t-test was conducted to compare the respondents score on institutional commitment for males and females. There was no statistically significant difference in scores for males $(M=3.12, S D=.609)$ and females $[M=3.05, S D=.608 ; t(178)=.683, \mathrm{p}=.495]$. Since the $\mathrm{p}$-value is greater than .05; it is not significant to say that there is difference between male and female respondents.

Second, to examine the difference between and within groups of more than three, Analysis of Variance (ANOVA) is taken as appropriate technique. Thus, a one-way between-groups analysis of variance was conducted to explore the difference based on experience, academic status and generation. Primarily, response based on experience was tested. Participants were divided into different groups (Group 1: 3-6 years; Group 2: 7-9 years; Group 3: 10-12 years). There was no significant statistical difference at the $p<.05$ level for the groups $[F(2,178)=2.732, p=.068]$. secondly, the academic status was tested and shows no significant differences between group means as determined by one-way ANOVA $[F(2,178)=$ $.656, p=.058]$.Finally, in order to examine whether there is a significant instructors' response difference between and within generations, statistical test was made and the result indicates that there is no statistically significant difference at the $p<.05$ level for the groups $[F(2,178)=2.899, p=.058]$.

In addition to the questionnaire, instructors orally reflected on the commitment of the universities to diversity. Except on mission and vision statements, majority of the instructors are not satisfied with the current status of institutional commitment.

To begin with, a female instructor from Ambo University stated:

There is an attempt of addressing diversity through different strategies. Just to list some of them: Affirmative action, making diversity part of the institution mission, celebrating nations and nationalities day. I think these are not only the initiatives higher education institutions should take to create inclusive environment in nations where diversity is the foundation for all programs and activities. For example, I didn't see any living diversity plan in my ten years stay at 
Volume 6 Issue 4 April 2018

the university. Diversity plan is helpful to guide institutional activities at all levels. Everything related to diversity is seasonal where programs and activities are arranged for formality than genuine implementation and promotion. Moreover, I didn't experience accountability and reward related to diversity except insufficient movements associated with gender issues.

Another respondent from Gondar University expounded his view on institutional commitment. He recounted

I think there are initiatives to address diversity in our university. Truly speaking, it is not for academic purpose. It is used solely to manage diversity flashpoints particularly among different ethnic groups. No one has a gut to speak about diversity in academic context. It is one of the most sensitive but glaring and incessant challenge. In fact, we celebrate nations and nationality's day, Women's day and others for the sake of media consumption. The reality is completely different and is camouflaged by surreptitious artificial propagations. I personally worry about this insidious effect for we have already started counting the cost. Serious conflicts among the students sometimes lead to loss of life. This is the consequence of window dressing approach.

In order to triangulate the results about institutional commitment to address diversity, the vision, mission, goals and core values are scrutinized and the following statements are drawn from the official documents of the selected universities. Jimma University states about diversity as one of its goals "to build a diverse global network in intercultural, curricular and co-curricular opportunities that make students globally competent". Gondar University also states its diversity commitment in its core values as "Gondar University promotes diversity in its policies and practices to prepare its learners to live and work successfully in an increasing diverse society". At Ambo University, diversity issues are treated in two subtitles under core values. The first one is general and the other deals with specific to gender dimension. The general statement goes "The University upholds educational and work environment in which all individuals and cultures are celebrated and respected for their unique talents and insights irrespective of ethnicity, gender, religion and physical and mental abilities and ensures justice in all opportunities". The specific gender based value is stated as "The University is committed to work hard toward achieving gender equity within the University and the society in general".

From third generation universities, Wolkite University described about diversity in its core values as an inclusive aspect stating "The University cultivates diverse religion, gender, special interest, and develop collaboration and shared vision". Mizan Tepi University describes diversity issues in its vision. It says "Mizan-Tepi University aspires to be the leading higher educational institution being center of excellence in education and research in areas of natural resources and cultural value utilization for development." Similarly, Assosa University incorporated diversity issues in the values and principles of the institution.

The guiding values of the higher education proclamation also states what institutions need to do to create welcoming campus climate for all. Specifically, article seven (7) sub article eleven (11) states "Democracy and multiculturalism" as one of the guiding values of the institutions. In relation to this, article 37 sub article 1(e) states the rights of the students on campus "students shall have the right to receive protection from any form of discrimination or harassment." From the statement, it is possible to deduce that institutions are also responsible to protect the rights of the students which include issues of diversity." Moreover, the institutions are expected to promote academic freedom on campus. Article 16(2) states "Every institution shall cultivate the culture of social responsibility in its academic community in the exercise of academic freedom."

Based on the responses of the participants issues of commitment to diversity has myriads of characteristics and implications for welcoming campus climate. Literature also shows the peculiar features of institutions with better commitment to diversity. For example, [22] in the article entitled "Toward a Diversity-Competent Institution" outlines 14 aspects as the major features of institutions committed to diversity in higher education. These are: Mission Statement, diversity definition, Leadership commitment, structure, diversity plan, diversity model, Assessment and Progress report, accountability and reward, visible diversity, academic diversity, healthy tension, contribution to society, pervasive ethos, diversity celebrations. The bottom line of the institutional commitment is creating conducive learning and teaching environment to achieve tripartite 
Volume 6 Issue 4 April 2018

missions of higher education institutions; teaching, research and community service.

\section{Conclusion and Recommendations}

Institutional commitment to diversity hinges on the planned programs and practices universities develop and promote to create healthy campus climate. Inculcating diversity issues in institutional policies and strategies is vital. However, it is not a guarantee to enjoy the fruits of learning, living and working together. Endorsing and enacting diversity- affirming perspective in all aspects of the institution is the indispensable move forward to make the difference. In Ethiopian universities context, it is possible to figure out two core points from the data. First and foremost, there are no sufficient plans and programs regarding diversity in explicit and independent status at all levels. Except gender based programs, there are no or little officially documented plans in all universities. Secondly, the available guides presented in mission and visions are not realized effectively. The practices are seasonal driven by political maneuver to control flashpoints even if there are movements in students' union/organization.

The study recommended the strategic approach in addressing diversity. This requires from critical planning phase at institution level to grassroots implementation of the policies and programs. Moreover, managing diversity should be seen from academic point of view than solely relying on administrative issues to settle flashpoints camouflaged by political orientation.

\section{Acknowledgements}

We exclusively acknowledge and deeply indebted to the research participants for providing us information to produce this article. In addition, we are grateful to academic and non- academic staff who involved directly and indirectly in the process of data collection in all institutions.

\section{References}

[1].M.Bryam \&G.Alfred, Becoming an intercultural mediator: A longitudinal study of residence abroad. Journal of Multilingual and Multicultural Development,2002, 23(5), 339-352.

[2].P.Arrendodo, Organizational Assessments for Planning Diversity Initiatives, A Workshop presented at Arizona State University on February $12^{\text {th }}, 2004$.
[3].E.R. Fox \&R.J. Norton, The Change Equation. Washington, DC: American Psychological Association, 1997.

[4].S. Hurtado,L.C. Alvarez,C.GillermoWann,M.Ceullar,L.Arellano, A Model for Diverse Learning Environments: The Scholarship on Creating and Assessing Conditions for Student Success UCLA Higher Education Research Institute, University of California, Los Angeles,2012.

[5]. M.C. Cress, Creating inclusive learning communities: The role of student-faculty relationships in mitigating negative campus climate. Learning Inquiry,2008, 2, 95-111.

[6]. P.Gurin, E. Day, G. Gurin, \& S. Hurtado, Diversity and higher education: Theory and impact on educational outcomes. Harvard Educational Review, 2002, 72(3), 330-366

[7]. F.J.Milem, The educational benefits of diversity: Evidence from multiple sectors. In M. Chang, D. Witt, J. Jones, \& K. Hakuta (Eds.). Compelling interest: Examining the evidence on racial dynamics in higher education,2003, (pp. 126-169). Stanford, CA: Stanford University Press.

[8] F.J.Milem,K.Hakua, The benefits of racial and ethnic diversity in higher education. In D. J. Wilds (Ed.), Minorities in higher education, 1999-2000, seventeenth Annual Status Report,2000, pp. 39-67. Washington: American Council on Education.

[9]. J.M.Chang,D.Witt,J.Jones \& K.Hakuta(Eds.), Compelling interest: Examining the evidence on racial dynamics in college and universities. Stanford: Stanford University Press,2003.

[10]. C.S.Herring, Convergent media computermediated communication: Introduction and theory. Paper presented at the panel on Convergent Media Computer-Mediated Communication, Internet Research 10.0, Milwaukee, WI, 2009, October.

[11]. R.A. Clayton-Pedersen,R.A., Parker,G.D. Smith,F.J. Moreno,\& H.D.Teraguchi, Making a real difference with diversity: A guide to institutional change. Washington: Association of American Colleges and Universities,2007.

[12]. F.J.Milem, J.M.Chang \&L.A.Antonio, Making diversity work on campus:A research-based perspective. Washington, DC: Association of American Colleges and Universities,2005. 
Volume 6 Issue 4 April 2018

[13]. T. Cox, creating the multicultural organization: A strategy for capturing the power of diversity. San Francisco, CA: Jossey-Bass, 2001.

[14].S.Choudhary \& P.Deshwal, Workforce Diversity management: Biggest Challenge for the 21st century Managers. International journal of Multidisciplinary Research, 2012,2(4): $74-87$

[15]. J.E.Keler, Ethnic federalism, fiscal reform, development and democratization in Ethiopia. African Journal of Political Science, 2002,7(1), 21-50.

[16]. L.Amith, The politics of contemporary language policy in Ethiopia. Journal of Developing Societies,2008, 24(2), 207-243.

[17]. K.Tronvoll, rights group cointernational: Ethiopia: A new start? (Report) N.P,2000.

[18]. T. Abera, "The influence of inter-ethnic attitude on inter-ethnic quality of interaction among A.A.U main campus Oromo, Amhara and Tigray students," 2010, Unpublished.
[19]. H.Afework, "Religious tolerance in Addis Ababa University,” 2009, Unpublished.

[20].D. Melkam,G. Ameyu, Interethnic relations among students of Jimma University. International Journal of Sociology and Anthropology, 2013, Vol. 5(5), pp. 179-191.

[21]. J.W. Creswell, Qualitative inquiry and research design: Choosing among five approaches. Thousand Oaks, CA: Sage, 2007.

[22]. S.O.Michael, toward a diversity-competent institution, 2007, Retrieved June 5, 2011, from http://www.uc.edu/content/dam/uc/diversity/docs/Tow ard_a_DiversityCompetent_Institution.pdf 